\title{
Comparison between the effects of propofol-ketamine and propofol- fentanyl for sedation in cataract surgery
}

\author{
Heidari SM'1, Shetabi HR², TarashiKashani $\mathbf{S}^{3}$ \\ 1. Professor of Anesthesiology, Faiz Medical Center, Isfahan University of Medical Sciences, Isfahan, Iran. \\ 2. Assistant Professor of Anesthesiology, Faiz Medical Center, Isfahan University of Medical Sciences, Isfahan, Iran \\ (Corresponding Author), Tel: +98-3138222532, Email: hamidshetabi@med.mui.ac.ir \\ 3. Student Research Committee, Al-Zahra Medical Center, Isfahan University of Medical Sciences, Isfahan, Iran.
}

\begin{abstract}
Background and Aim: Considering the importance of proper sedation in cataract surgery, this study was conducted to make a comparison between the effects of ketamine-propofol combination and fentanyl-propofol combination for sedation in phacoemulsification surgery. Methods: In this clinical trial study, 84 patients who were candidates for phacoemulsification cataract surgery were assigned to two groups. Each group consisted of 42 patients. Ketaminepropofol combination and fentanyl-propofol combination were used for induction of sedation for the first and second groups respectively. We assessed and compared sedation depth (using Ramsay score), hemodynamic parameters during operation and recovery, and satisfaction of the patients and surgeons between the two groups.

Results: There were no significant differences between the two groups in terms of baseline variables, demographic characteristics, sedation index and patient and surgeon satisfaction.

There was no significant difference between two groups in relation to blood pressure during operation and recovery periods but the heart rate at the 10th minute of the operation and at the beginning of the recovery in the ketofol group was significantly higher, and also the mean Spo2 was higher in the ketofol group at the 10th minute of operation. Patients in the ketofol group showed less hemodynamic changes.

Conclusion: Both combinations of ketamine-propofol and fentanyl-propofol were associated with the effective sedation, satisfaction of the patients and the surgeons. But generally, hemodynamic status was more stable in the patients in the ketofol group.

Keywords: Sedation, Ketamine, Propofol, Fentanyl, Cataract

Received: Jan7, 2019

Accepted: April 28, 2019
\end{abstract}

How to cite the article: Heidari SM, Shetabi HR, TarashiKashani S. Comparison between the effects of propofol-ketamine and propofol-fentanyl for sedation in cataract surgery. SJKU 2019;24(2):30-40. 


\section{مقايسه تاثير آرامبخشى برويوفول - كتامين با برويوفول - فنتانيل در جراحى كاتاراكت

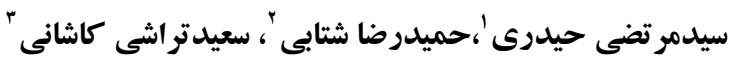

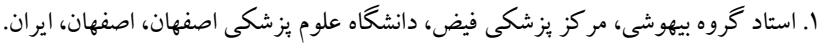

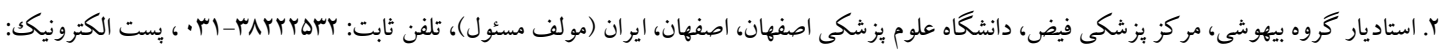 hamidshetabi@med.mui.ac.ir r. كميته تحقيقات دانشجوى، مركز يزشكى الزهرا، دانشگاه علوم يزشكى اصفهان، اصفهان، ايران.}

زمينه و هدف: با توجه به اهميت ايجاد آرام بخشى مناسب در عمل جراحى آبمرواريد، اين مطالعه با هدف مقايسه تأثير

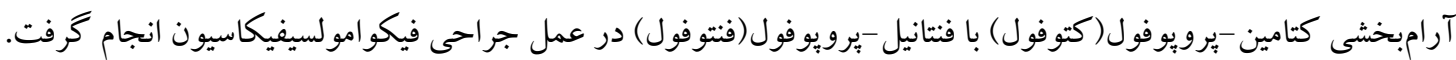
روش بررسى: در يكك مطالعه كار آزمايى بالينى، Af بيمار كانديد عمل جراحى فيكوامولسيفيكاسيون، در به طور تصادفى به دو بهو

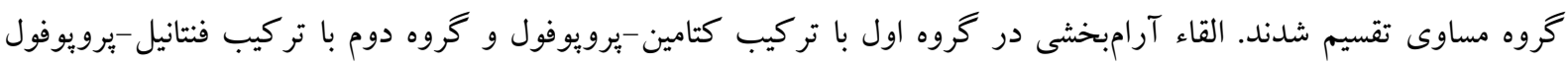

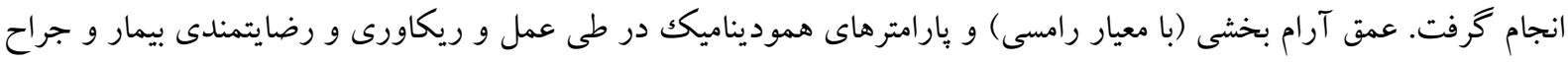
در دو گروه تعيين و مقايسه گرديد.

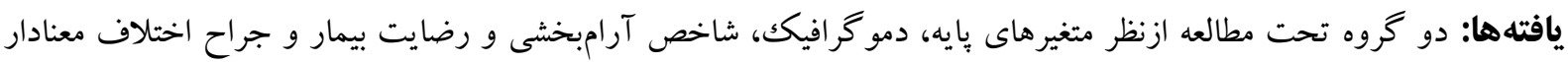

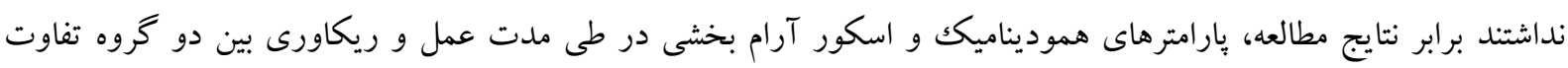

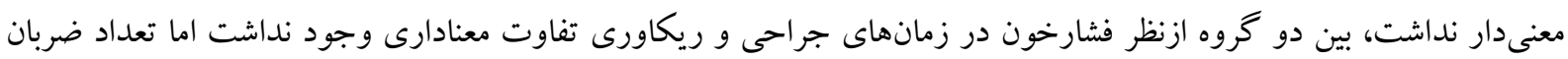

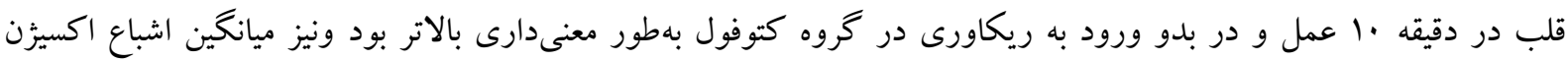

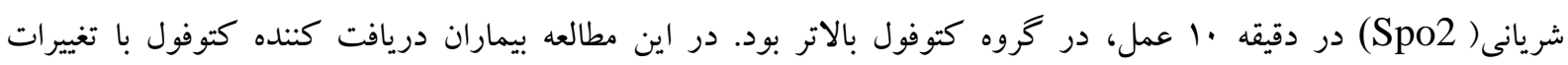
هموديناميك كمترى همراه بودند. نتيجه كيرى: هر دو تركيب از كتامين-يرويوفول و فنتانيل يرويوفول همراه با آرام بخشى مؤثر و رضايتمندى بيمار و جراح بودند؛ اما طور كلى، بيماران دريافت كننده كتوفول داراى ثبات بيشتر وضعيت هموديناميك بودند. كليد وازه ها: آرام بخشى، كتامين، برويوفول، فنتانيل، كاتاراكت

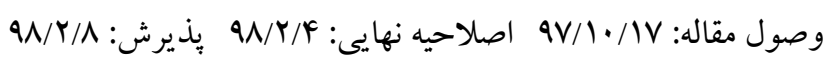


كتامين از مشتقات فن سيكليدين، آنتاكونيست انتخابى و غير رقابتى گيرنده ان-متيل-دى-آسيارتات (NMDA) كه باتصال به گيرندهاى إيوئيد و گيرندهاى سيخما، منجر به يك وضعيت به نام "بيهوشى انفكاكى" مىشود. مى توان از

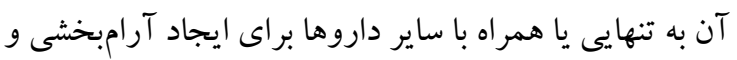
بى دردى در ضمن اقدامات تشخيصى و درمانى استفاده نمود. تركيب كتامين و برويوفول به صورت موفقيت آميزى مورد استفاده قرار گرفته است كه اين به علت خو اص متضاد هر دو دارو در اثرات هموديناميك و تنفسى بوده و در

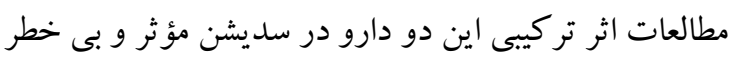

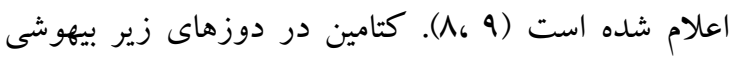
( علائم روانشناختى خفيف و همبجنين نيسا كموس و دوبينى

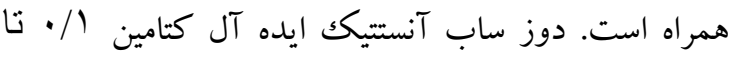

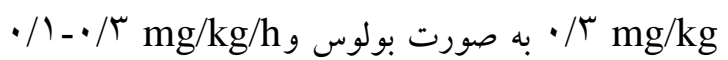

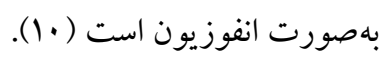
فنتانيل يك داروى اووييوئيد كو تاه اثر است. تركيب فنتانيل و ميدازولام جهت سديشن در فرآيندهاى دردناكك به كار

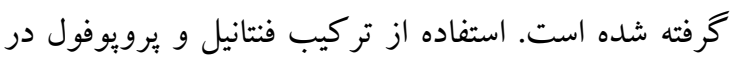
فر آيندهاى دردناكك با بىدردى و بيدار شدن سريع شدن سريع بيماران همراه است. در مطالعات خطر ديرسيون تنفسى

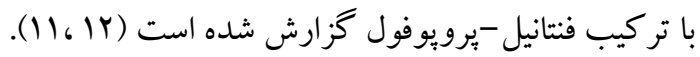
امروزه از تركيبات دارويى مختلفى براى فراهم آوردن آرامسازى حين يروسيجرهاى جراحى استفاده شده است

در بررسى متون مطالعهاى كه تأثير كتوفول با نسبت ؟: ا را با فنتوفول مقايسه كند يافت نشد لذا در مطالعه حاضر به بررسى اثربخشى دو تر كيب فوق بر كيفيت آرامبخشى حين جراحى كاتاراكت يرداختيم.

\section{مقدمه} عمل جراحى آب مرواريد يا كاتاراكت به خارج كردن عدسى طبيعى جشم (كه در اثر آب مرواريد، ناكار آمد و كدر شده است) و جايگزينى آن با لنز مصنوعى كفته

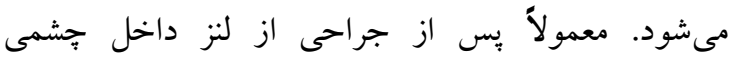
جايخزين عدسى جشم استفاده مىشود. روش جراحى فيكو امولسيفيكاسيون روش استاندارد و معمول عمل كاتاراكت است. عمل جراحى كاتاراكت و ويترورتينال شايعترين

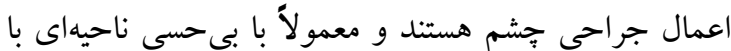
يا بدون سديشن انجام مى شود (Y، (I).

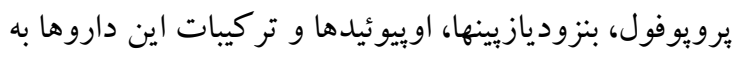
طور معمول براى سديشن استفاده مىشوند. جراحى كاتاراكت معمولاً در افراد مسن انجام مىشود. در سنين بالا

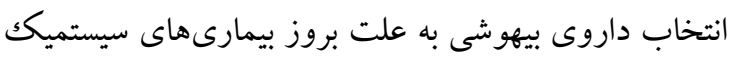

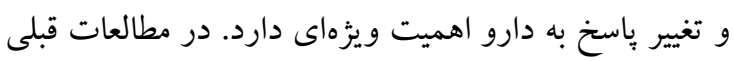

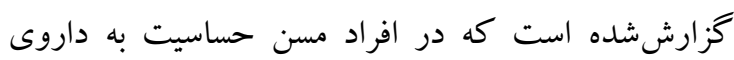
يرويوفول تا •ه-·r درصد و نيمه عمر ميدازولام نيز تا بيش از دو برابر افزايش مىيابند (F) ،r). با اين حال اثبات شده است كه اثر توهم زايى كتامين در افراد مسن بروز بيدا

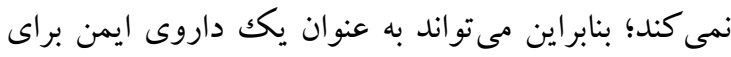

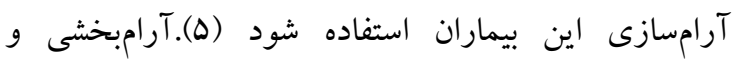
بىدردى وريدى به عنوان يكك روش بلدون خطر و مقرون به إنها

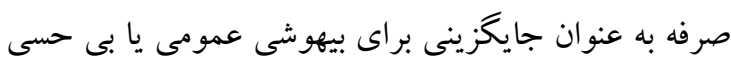
ناحيهاى بذيرفته شده است (9،V).

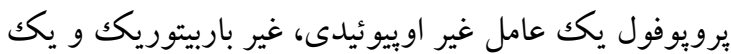
داروى سداتيو است كه داراى خاصيت ضد تهوع بوده و عوارض جانبى آن شامل ديرشن وابسته به دوز كارديوواسكولار و تنفسى است مى باشد. با توجه به اينكه يرويوفول از خاصيت ضد درد ذاتى برخوردار نيست، لازم است در يروسههاى دردناكك همراه با يكك داروى ضد درد نظير مخدر بكار رود (96V). 
نرمال سالين تزريق شد. سرنك كتوفول، حاوى ها ميلى ليتر برويوفول (٪ (•ا ميلى گرم / ميلىليتر) و ا ميلىليتر

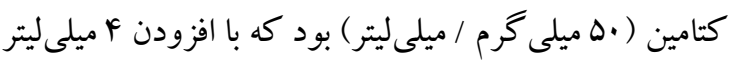

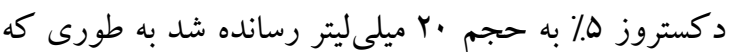

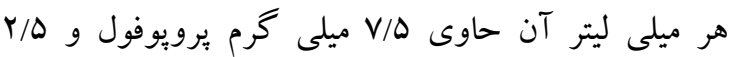

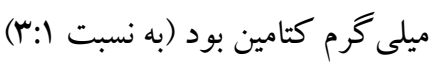

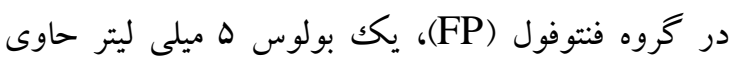

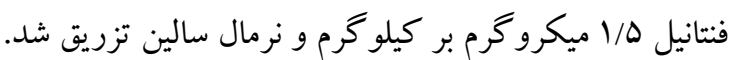

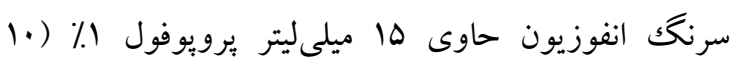

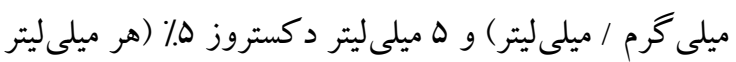

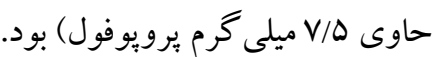

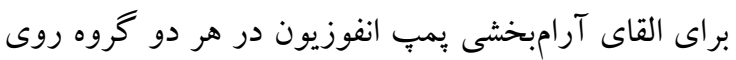

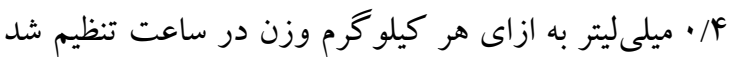

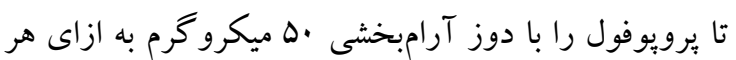

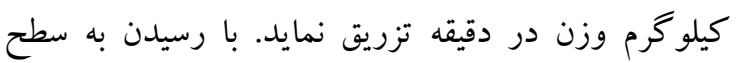

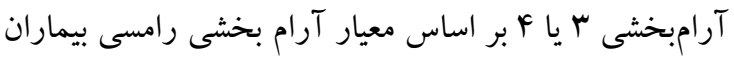

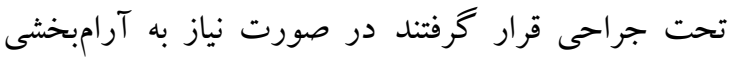

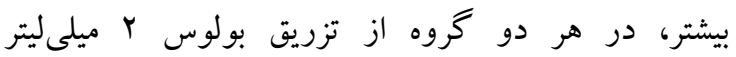
يرويوفول(با غلظت ه ميلى گرم در هر ميلىليتر) استفاده شد. طبق معيار آرام بخشى رامسى، سطح آرامبخشى بيمار به شش گريد تقسيم مىشود كه عبارت است از ا(كاملاً بيدار و مضطرب)، r (ساكت و آرما با همكارى كافى)،

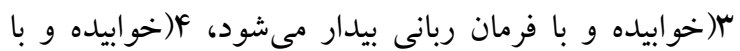
تحريك خفيفى بيدار مىشود ولى به تحريكات دردناكك واكنش شديد نشان مىدهد)، ه (واكنش آهسته به تحريك لهر دردناك يا تحريك صوتى)، و(عدم واكنش به تحريكات دردناكك يا تحريك صوتى بلند). جس از اتمام جراحى، بيماران تا زمان بهبودى بايدار (نمره 9

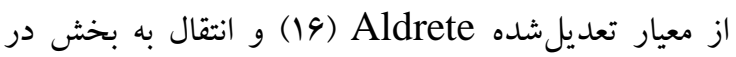
ريكاورى همجنان تحت مونيتورينگك قرار داشتند.

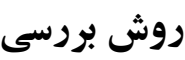

اين مطالعه كار آزمايى بالينى تصادفى شده دوسويه كوريس روسي از موافقت كميته اخلاق دانشگاه علوم يزشكى اصفهان و

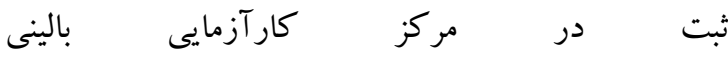
Ira9-IrqV در سال (IRCT2018416039326N2) در بيمارستان دانشگًاهى فيض انجام گرفت. معيار ورود به مطالعه شامل بيماران هr تا له سال

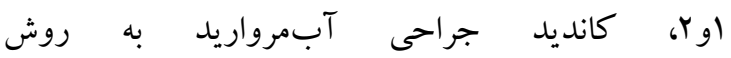
فيكو امولسيفيكاسيون با رضايت آكاهانه براى شركت درانديل دروريل مطالعه و عدم سابقه (حساسيت به داروهاى بيهوشى، ايست قلبى تنفسى، نارسايى احتقانى قلب، تروماى سر، كلو كوم، هييوتانسيون، شواهد افزايش فشار داخل مغزى، سايكوز، اسكيزوفرنى، عفونت فعال دستگاه تنفسى فوقانى، آسم و

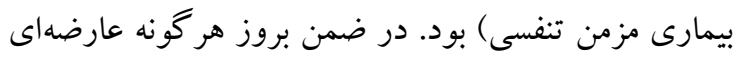

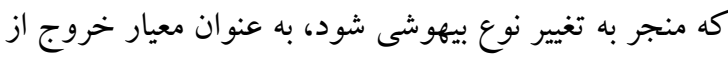
مطالعه در نظر كرفته شد. روش كور سازى بدينصورت بود كه بيماران و فرد

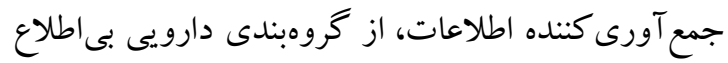
بودند .كليه بيماران براى انجام بيهوشى در شرايط سديشن و

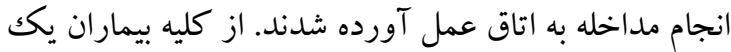

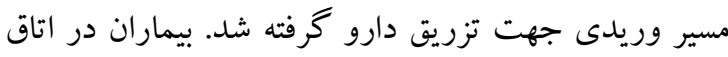

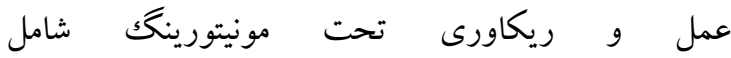

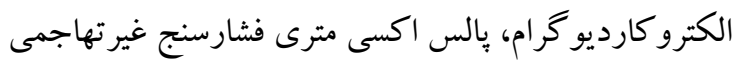

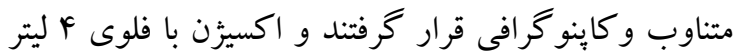
در دقيقه از طريق كانولاى بينى دريافت كردند. قبل از تزريق داروهاى آرام بخش، هر ه دقيقه در حين عمل و هر •ا دقيقه در ريكاورى (به مدت ·r دقيقه) ، تعداد ضربان قلب،فشارمتوسط شريانى (Mean arterial pressure) و درصد اشباع اكسيزن، اندازهيرى و ثبت شد. همجنين

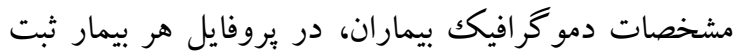
شد براى گروه كتوفول (KP) يكك دوز بولوس هـ ميلىليتر 
يافته ها

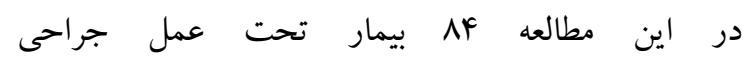

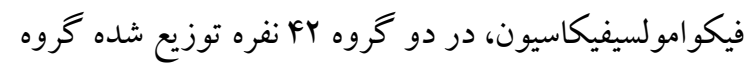

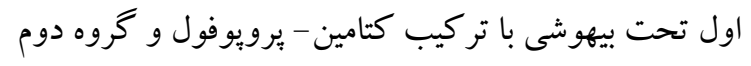

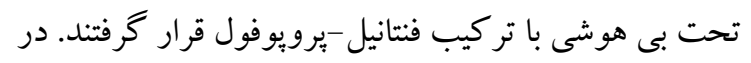

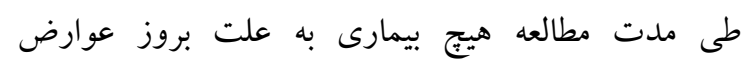

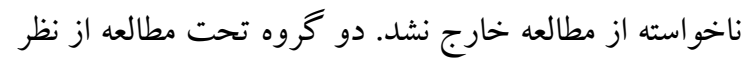

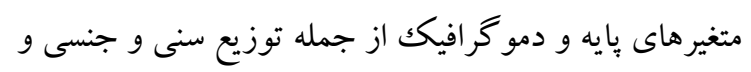
وزن و قد، BMI و معيار ASA اختلاف معنادار نداشتند

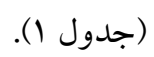

رضايتمندى با مقياس ليكرت (كاملاً راضى (ه)، راضى (F)،

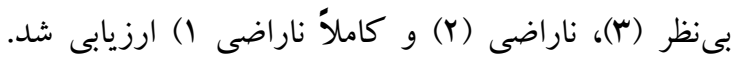
رضايت جراح در بايان جراحى و رضايت بيمار قبل از انتقال

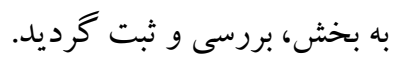

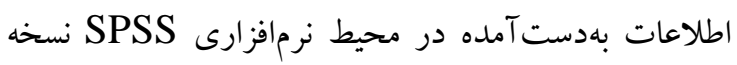

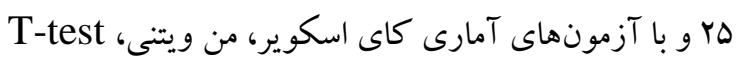

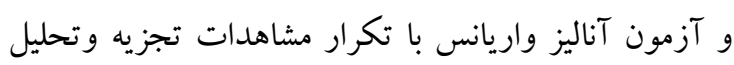
شد.

جدول ا: توزيع سن، جنس و وزن، ASA BMI در دو گروه تحت آرامبخشى با يُرويوفول-كتامين (1:r) و برويوفول-فنتانيل

\begin{tabular}{|c|c|c|c|c|}
\hline \multirow{2}{*}{ P. value } & \multicolumn{2}{|c|}{ كروه مطالعه } & \multirow{2}{*}{\multicolumn{2}{|c|}{ متغير }} \\
\hline & فنتانيل-يرويوفول & كتامين - برويوفول & & \\
\hline . & $9 V / 9 \pm I F / Y$ & $94 / 9 \pm 11 / 9$ & & ميانگين سن (سال) \\
\hline$\cdot / \mathrm{WV}$ & $V 1 / 9 \pm 19 / 4$ & $V \pm \pm r / F$ & & ميانكين وزن (كيلو گرم) \\
\hline .111 & $199 / 9 \pm 9 / 2$ & $194 / 9 \pm 1 V / 9$ & & ميانگين قد (سانتىمتر ) \\
\hline$\cdot / r 9$ & $r F / N F \pm F / \Delta 1$ & $r q / F I \pm r N / / Q$ & & ميانكين kg/m² ( BMI ) \\
\hline \multirow{2}{*}{$\cdot / r 9$} & $r \mu(\Delta F / \Lambda)$ & $r \wedge(99 / \mathrm{N})$ & مرد & \multirow[t]{2}{*}{ جنس فراوانى(درصد) } \\
\hline & $19(F \Delta / Y)$ & $\operatorname{lf}(T / / T)$ & 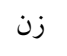 & \\
\hline \multirow{2}{*}{1} & $1 \cdot(Y \Gamma / \Lambda)$ & $1 \cdot(r / \Lambda)$ & 1 & \multirow{2}{*}{ ASA } \\
\hline & $\operatorname{rr}(\mathrm{VG/Y})$ & $\operatorname{rr}(\mathrm{VG/Y})$ & r & \\
\hline
\end{tabular}

تكرار مشاهدات، روند تغييرات فشارخون سيستول ودياستول نيز در دو گروه اختلاف معنى دار نداشت.

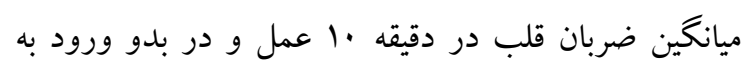
ريكاورى در دو گروه اختلاف معنىدار داشته و گروره

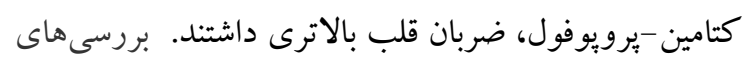

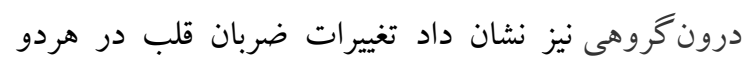

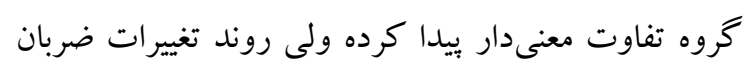
قلب، بين دو گروه اختلاف معنىدار نداشت (P=•/V)

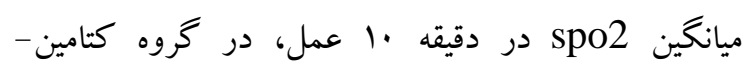

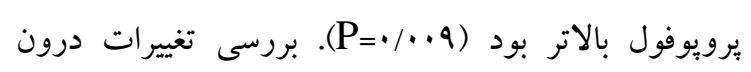

در جدول r، ميانگين و انحراف معيار پيارامترهاى

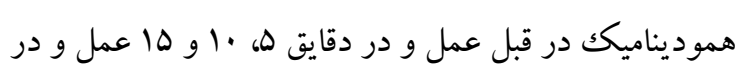

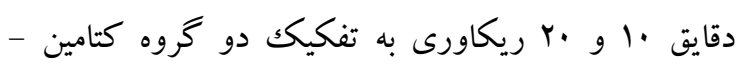
يرويوفول و فنتانيل -برويوفول نشان داده شده است. برابر نتايج مذكور، فشارخون سيتولى، دياستولى و ميانكين

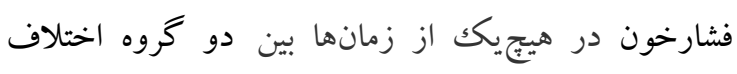

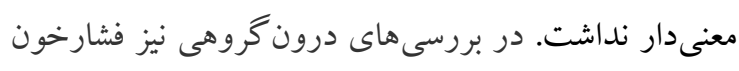

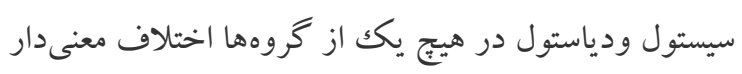

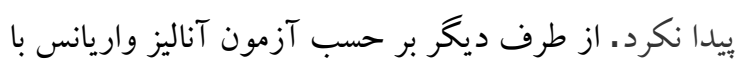


.....

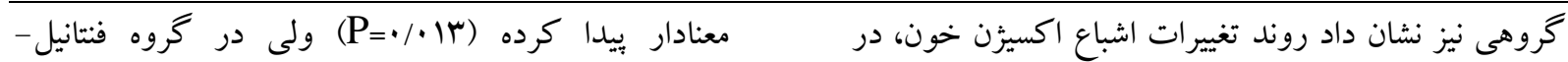

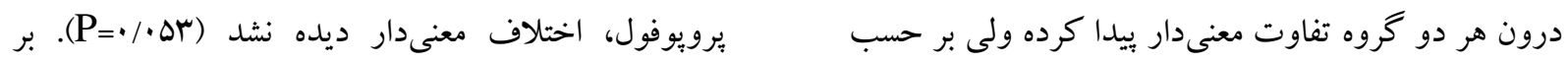

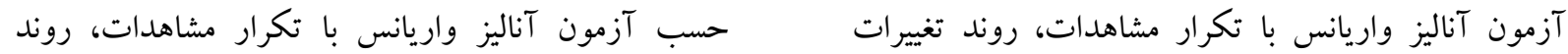
تغييرات MAP در بين دو گروه اختلاف معنى دار نداشت Spo2

شاخص MAP در هيجيك از زمانها بين دو گروه تفاوت معنىدار نداشت ولى بررسىهاى درونگروهى نشان داد، روند تغييرات MAP در گروه كتامين - بروبوفول تفاوت

جدول r: ميانگين و انحر اف معيار ضربان قلب و فشارخون در دو گروه

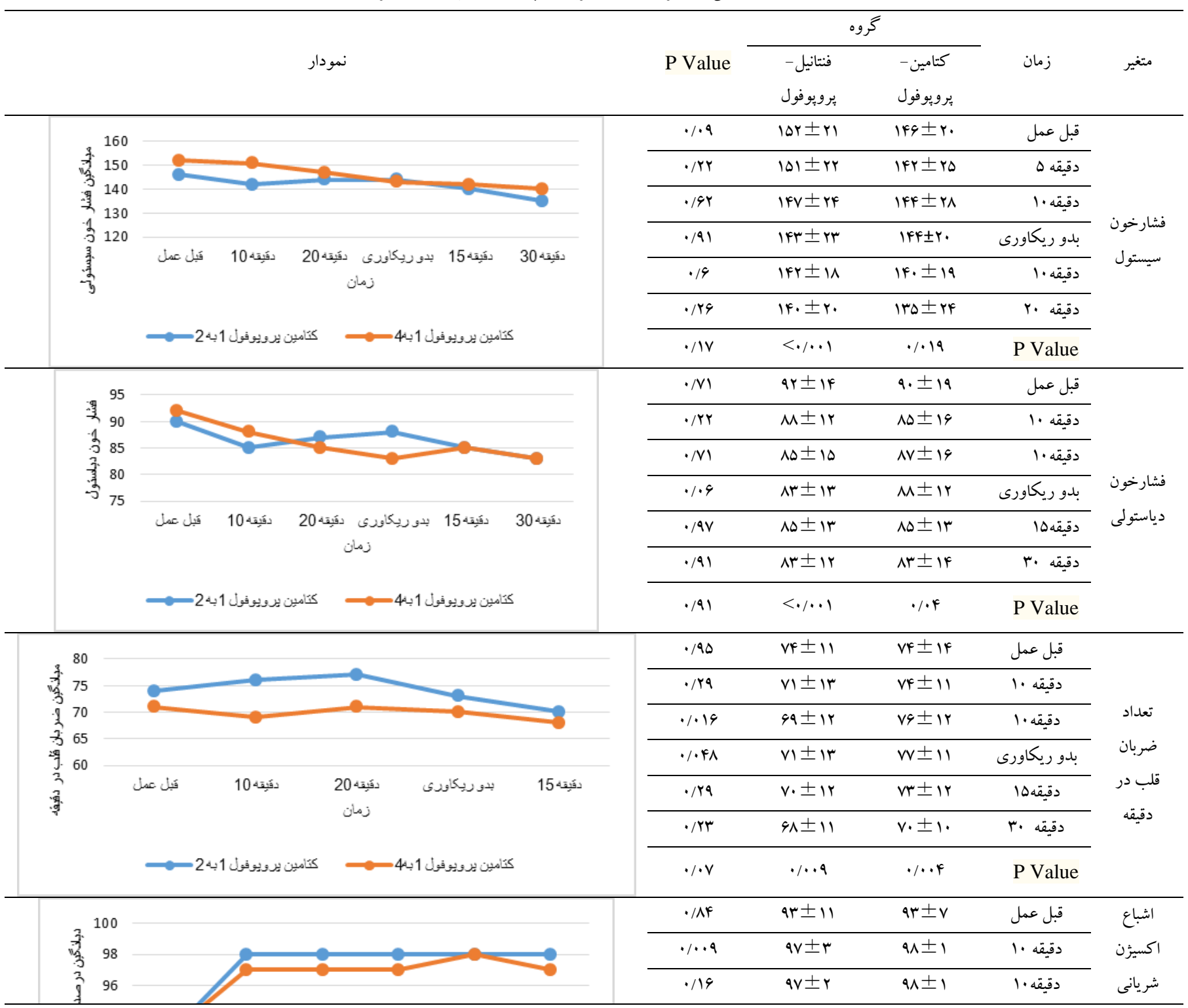

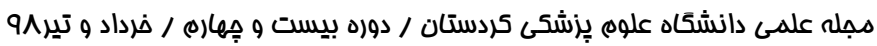




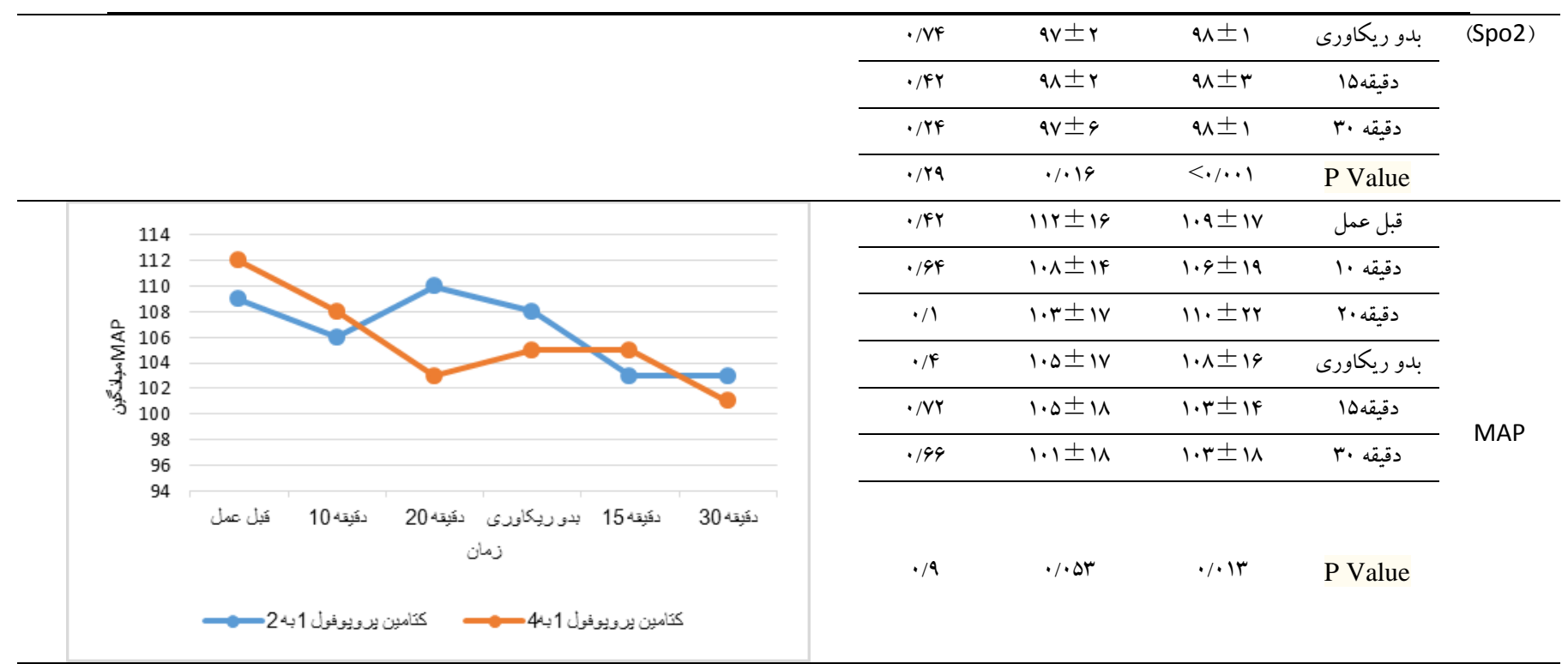

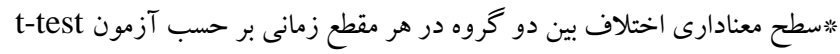

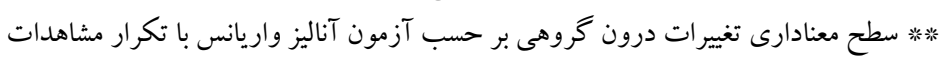

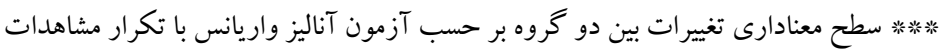

مذكور در طى مدت مداخله در بين دو گروه اختلاف

$$
\text { معنى دار نداشت (P=•/V) }
$$

بررسى رضايتمندى بيمار و يزشك كه نتايج آن در جدول F F

نشان داده شده است، اختلاف معنىدارى را بين دو گروه

نشان نداد.
برحسب نتايج جدول ب، ميانخين اسكور رامسى در هيج يك از مقاطع زمانى مطالعه، بين در دو كروه كتامينيرويوفول و فنتانيل -يرويوفول اختلاف معنىدار نداشت. در بررسىهاى درون كروهى، اسكور رامسى در طى زمان در هر دو كروه تفاوت معنىدار بيدا كرده ولى بر حسب آزمون آناليز واريانس با تكرار مشاهدات، روند تغييرات اسكور

جدول r: ميانگين و انحراف معيار اسكور رامسى در دو گروه

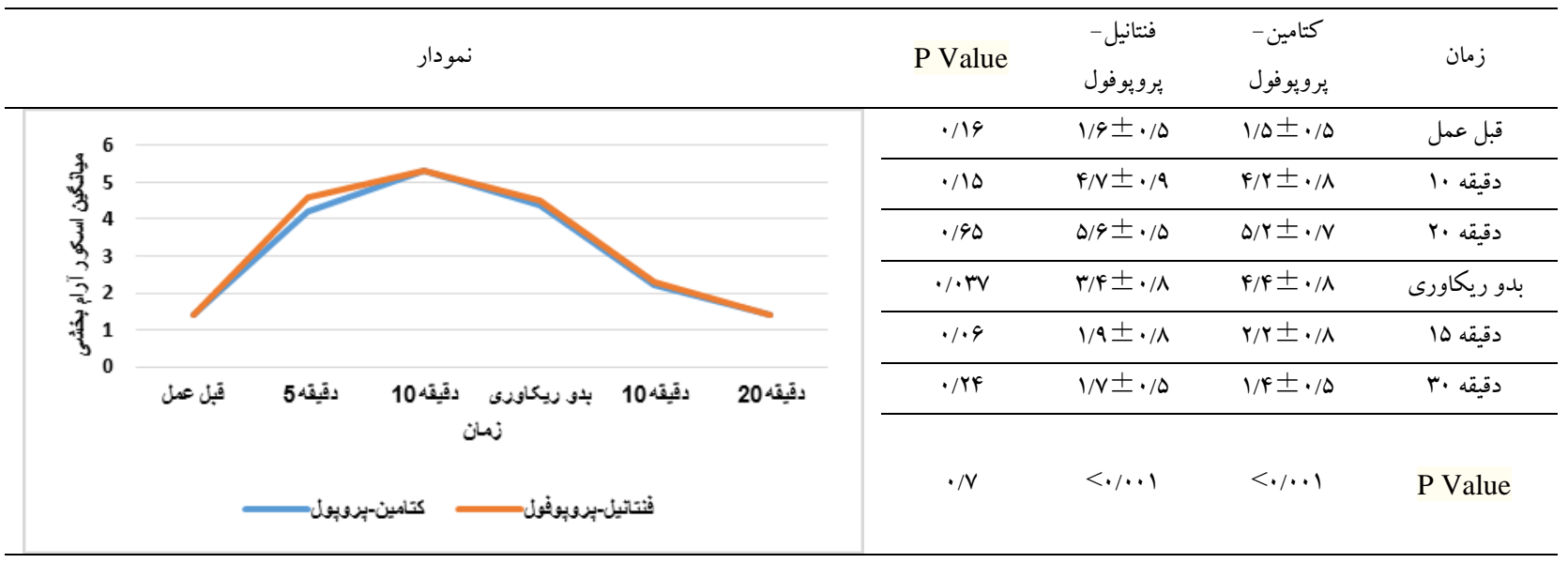

t-test سطح معنادارى اختلاف بين دو گروه در هر مقطع زمانى بر حسب آزمون

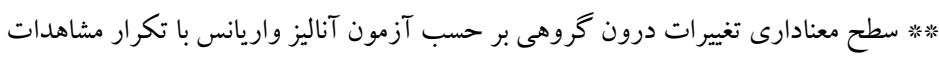




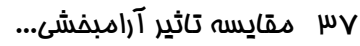



\begin{tabular}{|c|c|c|c|c|}
\hline \multirow{2}{*}{$\mathrm{P}$} & \multicolumn{2}{|c|}{ كروه } & & \multirow{2}{*}{ رضايتمندى } \\
\hline & فنتانيل -يرويوفول & كتامين - برويوفول & & \\
\hline \multirow{5}{*}{$\cdot / r \mid$} & $I(Y / F)$ & $\cdot(\cdot)$ & كاملاً ناراضى & \multirow{5}{*}{ رضايتمندى بيمار } \\
\hline & $r(\boldsymbol{F} / \Lambda)$ & $1(Y / F)$ & ن اراضى & \\
\hline & $\cdot(\cdot)$ & $\cdot(\cdot)$ & بى نظر & \\
\hline & $\Delta(11 / 9)$ & $1(Y / F)$ & راضى & \\
\hline & $\operatorname{rF}(\lambda))$ & $F \cdot(Q \Delta / r)$ & كاملاً راضى & \\
\hline \multirow{5}{*}{$\cdot 194$} & $\cdot(\cdot)$ & $1(Y / F)$ & كاملاً ناراضى & \multirow{5}{*}{ رضايتمندى جراح } \\
\hline & $\Delta(11 / 9)$ & $\Delta(11 / 9)$ & ن ناراضى & \\
\hline & $\cdot(\cdot)$ & $\cdot(\cdot)$ & بى نظر & \\
\hline & $q(Y Y / F)$ & $q(\mid F / T)$ & نسبتاً راضى & \\
\hline & $\mathrm{r} \wedge(99 / \mathrm{V})$ & $r \cdot(V \backslash / f)$ & كاملاً راضى & \\
\hline
\end{tabular}

و خروج بيمار از مطالعه گُردد، مشاهده نشد (هر جند كه دو

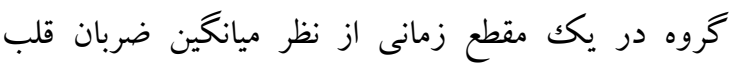

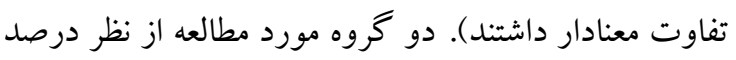
اشباع اكسيزن خون اختلاف معنىدار داشته و اشباع اكسيزن

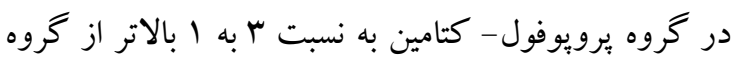

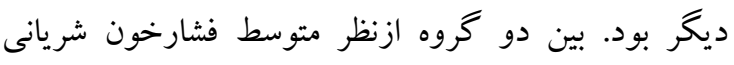
تفاوتى وجود نداشت. با توجه به يايين تر بودن تعداد ضربان

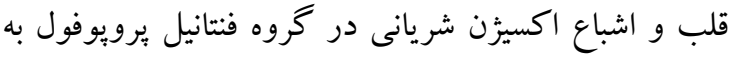
نظر مىرسد كه تركيب يرويوفول و كتامين، ثبات قلب و عروق را بيشتر از تركيب برويوفول فنتانيل فراهم مى كند. در يكك مطالعه كه توسط Tosun و همكاران درسال انجام شد، بيماران به صورت تصادفى تحت ب..V آرامبخشى با يرويوفول- كتامين و يرويوفول-فنتانيل قرار كرفتند. يافتها نشان داد كه ضربان قلب و ميزان تنفس در كروه يرويوفول-فنتانيل به طور معنىدارى كمتر بود. گرجه هر دو گروه در طى آندوسكويى آرام بخشى مناسب طرون برون داشتند، بايدارى هموديناميك و عمق آرام بخشى در ميان در اين مطالعه AF بيمار كانديد جراحى آب مرواريد در دو

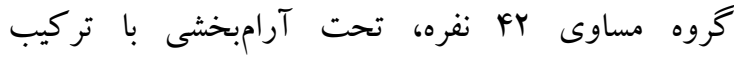

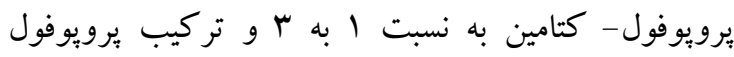

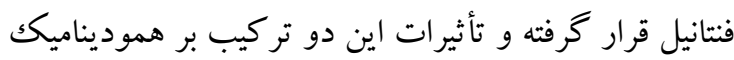

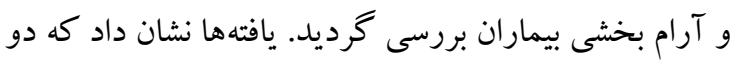

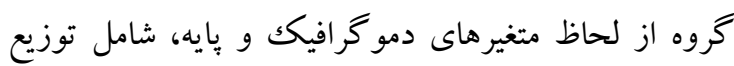

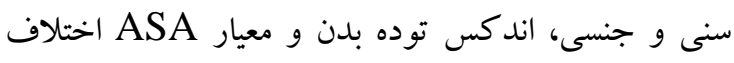
معنىدار نداشتند لذا تفاوتهاى مشاهده شده بين دو كرون ترده ازنظر بِاسخ هموديناميك و وكيفيت آرامبخشى، احتمالاً مربوط به نوع تركيب دارويى مورد استفاده بوده است.

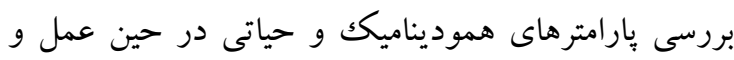
ريكاورى نشان داد، هيج كدام از دو تر كيب فوق داراى آثار سوئى بر علائم حياتى بيمار نبوده و در مجموع، موردى از

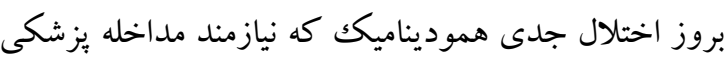


كيفيت آرامبخشى در گروه كتامين بيشتر از گروه فنتانيل بود. با توجه به نمره رضايتمندى جراح و و بيمار از فرايند

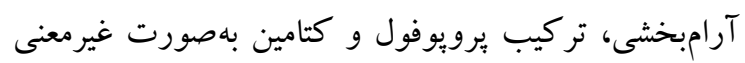
دارى مؤثرتر بود. Chandar

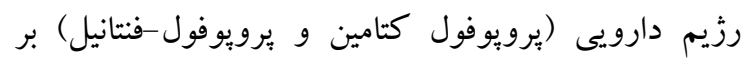

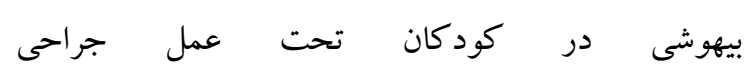

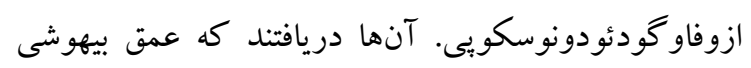

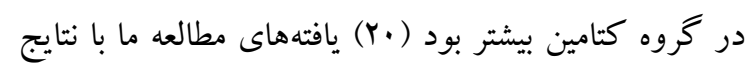
مطالعه Chandar همر مراستا است.

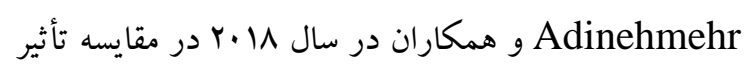

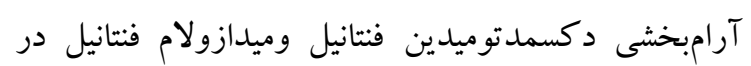

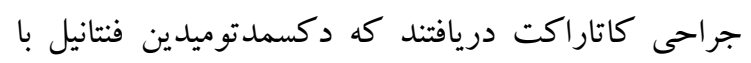

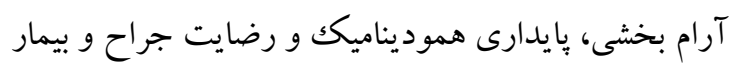

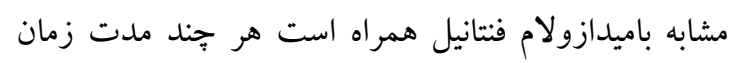
ريكاورى طولانى مى گردد (Y) (Y).

نتيجه كيرى

مطالعه ما نشان داد استفاده از تركيب كتامين -برويوفول و فنتانيل برويوفول در جراحى كاتاراكت با آرامبخشى مؤثر و رضايت بيمار و جراح همراه است. تغييرات فشارخون در دو كروه تفاوت معنىدارى نداشت اما درمجموع، بيماران

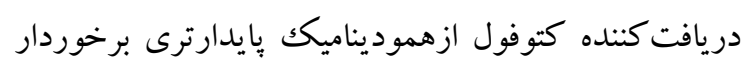
بودند.

\section{تشكر و قدرانى}

مقاله حاضر، حاصل پايان نامه دكتراى حرفهاى در در رشته

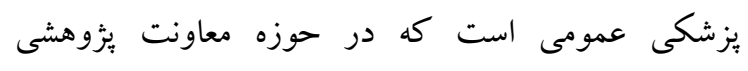

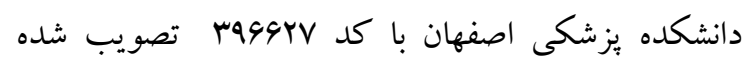
IR.MUI.REC1396.3.627 است. كداخلاقى مقاله مى باشد. نويسند كان مقاله بدينوسيله ازهمكارى معاونت دماله

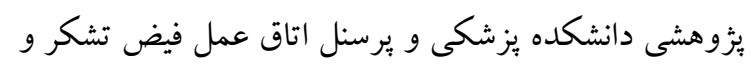

$$
\text { قدردانى مىنمايند. }
$$

گيرندگان كتامين بيشتر بود نتايج مطالعه حاضر همسو با يافنه هاى مطالعه Tosun است (IV) (IV). Nalini را كه تحت عمل جراحى عقيمى قرار گرفتند، مورد : ASA

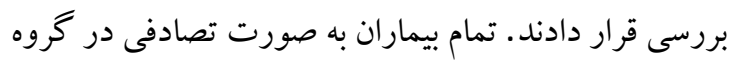

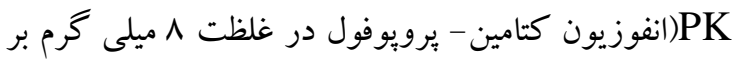

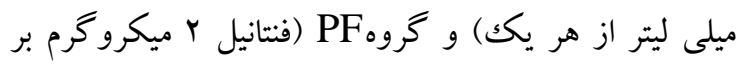
كيلو گرم و سبس يكك تزريق مداوم ^ ميلى گرم بر ميلى ليتر

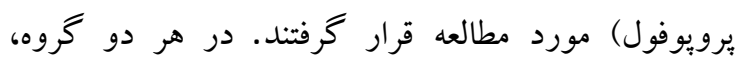

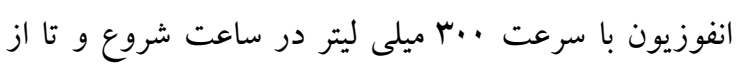

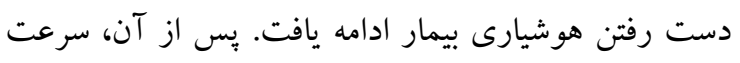

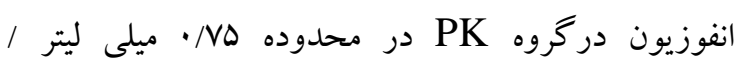

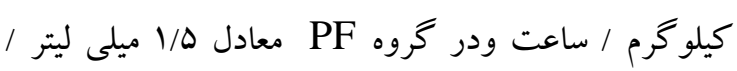

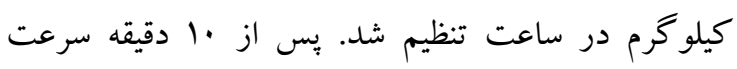

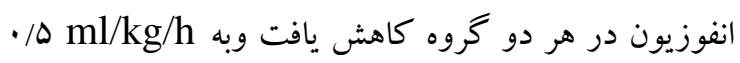

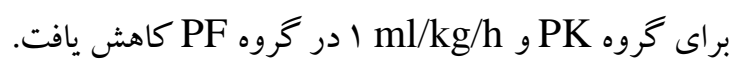
نتايج نشان داد كه كاهش فشار خون سيستوليك و و وره

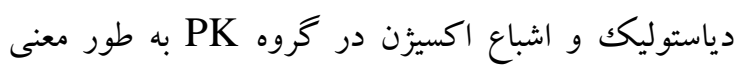

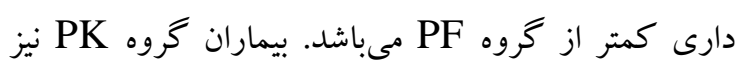
شرايط جراحى و بهبودى بهتر داشتند. نويسندكان نتيجه كرفتند كه بروبوفول كتامين تركيبى بى خطر است و مى ونى تواند يكك روش جايكزين براى تركيب بروبوفول و فنتانيل باشد (11). Khutia آرامبخشى كتامين برويوفول و فنتانيل برويوفول در كود كان تحت جراحى كوتاه اورزانس مشاهده كردند كه افت

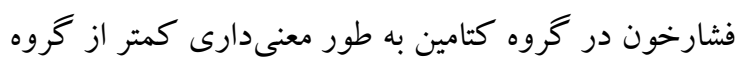

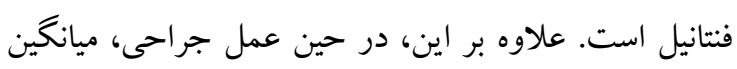

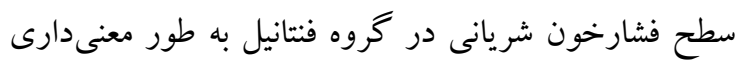

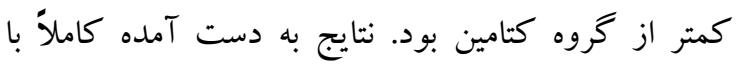

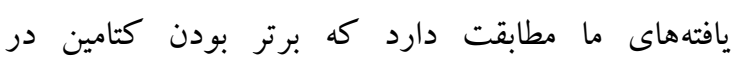

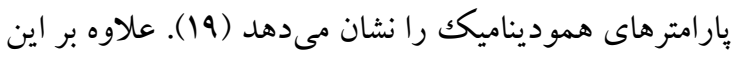




\section{Reference}

1. Vann MA, Ogunnaike BO, Joshi GP. Sedation and anesthesia care for ophthalmologic surgery during local/regional anesthesia. Anesthesiology 2007;107:502-8.

2. Merali FI, Schein OD, Berenholtz SM. High-value care for cataract surgery: questioning the utility of routine preoperative medical evaluation. Qual Manag Health Care 2018;27:178-9.

3. Moshiri E, Yazdi B, Khalili M. The comparison effect of midazolam with propofol on pre-operative anxiolysis. Arak Med Univ J 2009;12:87-94. [In Persian]

4. Kurdi MS, Deva RS. A comparison of two different proportions of ketofol with fentanylpropofol for sedoanalgesia for tubal sterilization by mini laparotomy: A randomized doubleblind trial. J Obstet Anaesth Crit Care 2015;5:84-9.

5.Yağan Ö, Karakahya RH, Taş N, Küçük A. Comparison of dexmedetomidine versus ketamine-propofol combination for sedation in cataract surgery. Turk J Anaesthesiol Reanim 2015;43:84-90.

6. Lee JH. Anesthesia for ambulatory surgery. Korean J Anesthesiol 2017;70:398-406.

7. Sato M, Horiuchi A, Tamaki M, Ichise Y, Kajiyama M, Yamamoto Y, et al. Safety and effectiveness of nurse-administered propofol sedation in outpatients undergoing gastrointestinal endoscopy. Clin Gastroenterol Hepatol 2019;17:1098-1104.

8. Zanos P, Moaddel R, Morris PJ, Riggs LM, Highland JN, Georgiou P, Pereira EF, Albuquerque EX, Thomas CJ, Zarate CA, Gould TD. Ketamine and ketamine metabolite pharmacology: insights into therapeutic mechanisms. Pharmacol Rev 2018;70: 621-660.

9. Frizelle HP, Duranteau J, Samii K. A comparison of propofol with a propofol ketamine combination for sedation during spinal anesthesia. Anesth Analg 1997;84:1318-22.

10. Gorlin AW, Rosenfeld DM, Ramakrishna H. Intravenous sub-anesthetic ketamine for perioperative analgesia. J Anaesthesiol Clin Pharmacol 2016;32:160-7.

11.Berkenbosch JW, Graff GR, Stark JM, Ner Z, Tobias JD. Use of a remifentanil-propofol mixture for pediatric flexible fiberoptic bronchoscopy sedation. Pediatric Anesthesia 2004; 14:941-6.

12. Yuosef GT, Elsayed KM. A clinical comparison of ketofol (ketamine and propofol admixture) versus propofol as an induction agent on quality of laryngeal mask airway insertion and hemodynamic stability in children. Anesth Essay Res 2013;7:194-9.

13. Shetabi H, Nazemroaya B, Shafa A, Sarlak S. comparison of the efficacy of two-drug combination, ketofol and fenofol, on sedation and analgesia in patients under the surgery of port catheter placement and removal. J Isfahan Med Sch 2019;36: 1421-7. [In Persian]

14. Nazemroaya B, Majedi MA, Shetabi HR, Salmani S. Comparison of Propofol and Ketamine Combination (Ketofol) and Propofol and Fentanyl Combination (Fenofol) on 
Quality of Sedation and Analgesia in the Lumpectomy: A Randomized Clinical Trial. Adv Biomed Res 2018;7:134.

15. Shetabi H, Golparvar M, Ghanbardezfoli S, Torfenejad M. Sedative and analgesic efficacy of propofol-ketamine and propofol-remifentanil during painful procedures in children with acute lymphoblastic leukemia. Iran J Ped Hematol Oncol 2018;8:87-96.

16. White PF, Song D. New criteria for fast-tracking after outpatient anesthesia: a comparison with the Modified Aldrete's Scoring System. Anesth Analg 1999;88:1069-72.

17.Tosun Z, Aksu R, Guler G, Esmaoglu A, Akin A, Aslan D, et al. Propofol-ketamine vs propofol-fentanyl for sedation during pediatric upper gastrointestinal endoscopy. Paediatr Anaesth 2007;17:983-8.

18. Kb N, Cherian A, Balachander H, Kumar C Y. Comparison of propofol and ketamine versus propofol and fentanyl for puerperal sterilization, a randomized clinical trial. J Clin Diag Res 2014;8:GC01- GC04.

19. Khutia SK, Mandal MC, Das S, Basu SR. Intravenous infusion of ketamine-propofol can be an alternative to intravenous infusion of fentanyl-propofol for deep sedation and analgesia in paediatric patients undergoing emergency short surgical procedures. Indian $\mathbf{J}$ Anaesth 2012;56:145-50.

20.Chandar R, Jagadisan B, Vasudevan A. Propofol-ketamine and propofol-fentanyl combinations for nonanesthetist-administered sedation. J Pediatr Gastroenterol Nutr 2015;60:762-8.

21.Adinehmehr L, Shetabi H, Motieian M. A comparison of sedative effect of dexmedetomidine-fentanyl versus midazolam-fentanyl during cataract surgery with phacoemulsification technique. J Isfahan Med Sch 2018;36:1009-1. [In Persian] 